\title{
UNA EVA MODERNA, ÚLTIMA NOVELA DE CONCEPCIÓN GIMENO DE FLAQUER
}

\author{
$\mathrm{M}^{\mathrm{a}}$ de los Ángeles AyAla \\ Universidad de Alicante
}

La figura de Concepción Gimeno de Flaquer (1850-1919) ha suscitado entre los estudiosos del siglo XIX escaso interés. Los trabajos bibliográficos sobre su vida y obra apenas superan media docena de artículos (Bieder, 1990 y 1993; Muñoz Olivares, 2000; Ramos Scandón, 2001; Ayala, 2005; Chozas Ruiz-Belloso, 2005; Hibbs-Lissorgues, 2006). Frente a la parquedad con que ha sido tratada esta novelista y ensayista en fechas recientes debemos subrayar que en su época fue una autora conocida tanto en España como en Hispanoamérica y que sus obras merecieron reseñas en los principales periódicos del momento ${ }^{1}$. Su participación activa en los círculos intelectuales de su época, como el Ateneo, el Círculo de Bellas Artes,

1. Vid., entre otras, las siguientes reseñas: Anónimo, «Reseña de Evangelios de la mujer», La Época, XI-20, 1899; Cárdenas, J. de, «Reseña de La mujer juzgada ante el hombre», Revista Contemporánea 9, 43 enero-febrero de 1883; Cortázar de Serante, «Reseña de Evangelios de la mujer», Revista Gallega, 15 de abril de 1900; Guerrero, T., «Reseña de En el salón y en el tocador. Vida social. Cortesía. Arte de ser agradable», El Álbum Ibero-Americano, 7 de abril de 1899; Martínez, S., «Reseña de La mujer española. Estudios acerca de su educación y sus facultades intelectuales», El Correo de la Moda, XXVII, 1877. Así mismo noticias sobre sus actividades las encontramos en los siguientes artículos publicados en vida de la autora: Bolaños Cacho, M., «Siluetas españolas: Concepción Gimeno de Flaquer», El Álbum de la mujer, enero de 1888; Guerrero, T., «Concepción Gimeno de Flaquer», La Ilustración Española y Americana, 30 de noviembre de 1890; Matheu, J. M., «Concepción Gimeno de Flaquer en el Ateneo», El Álbum Ibero-Americano, 12, 30 de marzo de 1891; Pérez, M., «Concepción Gimeno de Flaquer», La Ilustración Nacional, 16 de diciembre de 1890; Salvador, L., «Bocetos literarios: Concepción Gimeno de Flaquer», Revista Contemporánea, 91, julio-septiembre de 1893. 
la Unión Ibero-Americana de Madrid, otorgó a sus trabajos intelectuales y literarios una proyección nada desdeñable, que contrasta enormemente con el silencio que ha rodeado a la figura de esta escritora desde su muerte en 1919. Recordemos, entre otras, las conferencias pronunciadas en el Ateneo Científico y Literario -Civilización de los antiguos pueblos mexicanos, 17 de junio de 1890; Mujeres de la revolución francesa, 1891; Ventajas de instruir a la mujer y sus aptitudes para instruirse, 6 de mayo de 1895; El problema feminista, 1903-, en la Unión Ibero-Americana -Civilización mexicana en época precolombina; La mujer antigua y la mujer de espíritu moderno-, en el Círculo de Bellas Artes -La mujer y el arte-, en la Associazione della Stampa di Roma -La mujer italiana en el arte y en la historia, 3 de mayo de 1906-. En este sentido también cabe recordar que su labor como intermediaria cultural entre España y América fue premiada con un reconocimiento explícito de los gobiernos de México y Venezuela y homenajeada por esta misma labor por el Centro Catalán de La Habana.

El trabajo intelectual de esta escritora nacida en Alcañiz (Teruel) persigue dos objetivos fundamentalmente; uno, el mencionado en líneas anteriores, favorecer el intercambio cultural entre España y los países hispanoamericanos que, hasta tiempos relativamente recientes, habían pertenecido a la corona española y, el otro, la defensa de su propio sexo. Concepción Gimeno comienza su trayectoria literaria en los medios periodísticos de su época. Su primer artículo -«A los impugnadores del bello sexo»- aparece el 7 de noviembre de 1869 en el periódico zaragozano El Trovador del Ebro. A este artículo le seguirán otros muchos publicados en El Correo de la Moda (Madrid), El Mundo Ilustrado (Barcelona), La Madre de Familia (Granada), Flores y Perlas (Madrid), La Mujer (Madrid), Argos (Madrid), La Familia (Madrid), El Parthenon (Barcelona), El Heraldo Granadino (Granada), La Basílica Teresiana (Salamanca), entre otras revistas. Labor periodística que se completa con la fundación y dirección de La Ilustración de la Mujer en 1873 en Barcelona ${ }^{2}$ y El Álbum de la Mujer en México (1883)³, además de

2. La Ilustración de la Mujer. Revista quincenal. Órgano de la Asociación benéfica de señoras «La Estrella de los Pobres». Ocho páginas de 248 x $162 \mathrm{~mm}$. Dos cols. Imprenta de Gil Gelpi y Ferra, Pez, 6. Según consta en el Catálogo de publicaciones periódicas existentes en la Hemeroteca Municipal de Madrid, 1661-1930 (1933: 67), comenzó en junio de 1873. Sin embargo la propia autora señala en su obra La mujer española que fue el primero de marzo cuando se fundó dicha revista con el propósito de favorecer el acercamiento de la mujer a la educación. No se conservan todos los números de la revista, estando depositados en la Biblioteca Nacional de Madrid los números correspondientes al periodo comprendido entre el 31 de mayo de 1875 al 30 de diciembre de 1876 y en la Hemeroteca Municipal de Madrid los correspondientes al lapso temporal del 15 de agosto de 1875 al 1 de junio de 1877. Vid. el trabajo de Rodríguez Sánchez (2005).

3. Aunque en los escasos trabajos que sobre la escritora existen se da como fecha de publicación de El Álbum de la Mujer la de 1884, según Eduardo del Valle, autor de la biografía que se inserta 
dirigir desde 1890 a 1892 la revista madrileña El Álbum Ibero-Americano, cuya propiedad sustentaba su marido, el conocido periodista Francisco de Paula Flaquer y Fraise ${ }^{4}$.

En el corpus literario de Concepción Gimeno se perciben claramente dos facetas: el ensayo y la novela, que se sustentan en su determinación de contribuir a erradicar las viejas ideas que condenan a la mujer a una vida puramente vegetativa. La escritora desde el ensayo o mediante el placentero molde novelesco combatirá, como Emilia Pardo Bazán y Concepción Arenal, sus más ilustres coetáneas, todos aquellos aspectos de la vida de la mujer que, desde su posición ideológica, están en contra de su propia dignidad. Debemos destacar en este sentido sus trabajos La mujer española (1877), La mujer juzgada ante el hombre (1882), La mujer juzgada por una mujer (1882), Mujeres. Vidas paralelas (1893), Evangelios de la mujer (1900), La mujer intelectual (1901), entre otras. Obras en las que analiza desde el punto de vista sincrónico y diacrónico el papel de la mujer en sus respectivas sociedades, pues el objeto de estudio de Concepción Gimeno no se reduce en exclusividad a la mujer española, sino que analiza desde una perspectiva histórica cómo avanza la causa feminista en países tan alejados de su entorno como Australia y $\mathrm{China}^{5}$, aunque, evidentemen-

como prólogo a su novela ¿Culpa o expiación? Novela original con retrato y biografía de la auto$r a$ ( $4^{\circ}$ ed., 1890), el primer número apareció el 8 de septiembre de 1883. Eduardo del Valle aporta numerosos datos sobre la mencionada revista. Así, por ejemplo, señala su carácter semanal -salía los domingos-, la inserción de numerosas ilustraciones litografiadas, éxito alcanzado no sólo en México sino en el resto de países Hispanoamericanos en los que la revista se distribuía. Comenta, igualmente, el contenido de la misma, que conjugaba la creación literaria -artículos y poesía- con crónicas de la vida social mexicana y ofrece una larga lista de colaboradores que procedían tanto de Hispanoamérica como de España. Entre otros, cita las siguientes firmas: Valera, Menéndez Pelayo, Zorrilla, Joaquina Balmaceda, Emilia Pardo Bazán, Josefa Pujol de Collado, Grilo, Salvany, Martín de la Guardia, Obligado, Bertis, Palma, Rafael Nuez, Fernando Cruz, Isaacs, Castañeda, Martí, Fernández Montalvo, etc.

4. Inició su andadura en Madrid en 1883. Se publicaba los días 7, 14, 22 y 30 de cada mes. La suscripción costaba nueve pesetas al trimestre. 10 o más pp. -343 x $250 \mathrm{~mm}$. Tres cols., con grabados. Se imprimía en los talleres de Alfredo Alonso, calle del Soldado, 8. Quincenalmente regalaba a los suscriptores la revista de modas La Elegancia. Cuando Concepción Gimeno comienza a dirigirla aparece con el rótulo El Álbum Ibero Americano. Ilustración semanal. La redacción y administración de la misma estaba situada en la calle Campomanes, 3, principal.

Para una información de conjunto sobre la labor literaria y periodística de Concepción Gimeno de Flaquer vid. el trabajo de Simón Palmer, (1991. 363-374). También puede consultarse la siguiente dirección: http://www.escritorasypensadoras.com/fichatecnica.php/54.

5. En su obra Los evangelios de una mujer (1900) traza, en la segunda parte de la misma, una amplia e interesantísima panorámica general sobre el movimiento feminista, analizando la situación de la mujer en zonas geográficas tan distintas y distantes entre sí como las siguientes: América de Norte, Inglaterra, Fracia, Italia, España, México y Sud-América, Rusia, Alemania, Suecia, Noruega, Austria-Hungría, Suiza, Bélgica, Polonia, Holanda, Australia y China. Es evidente que Concep- 
te, insista mucho más en el análisis y censura del comportamiento de sus compatriotas. Ideología feminista que se configura en base fundamental de buena parte de sus narraciones, como sucede, desde luego, en el objeto de este trabajo: Una Eva moderna, relato corto que se publica en la colección de El Cuento Semanal el 26 de noviembre de 1909.

Concepción Gimeno de Flaquer presenta en esta novela el reiterado tema del adulterio, preocupación constante de la sociedad decimonónica y objeto de análisis que fecunda buena parte de la producción narrativa y dramática del periodo realista-naturalista español. Pese al amplio número de novelas centradas en este tema, Concepción Gimeno consigue insuflar nuevos aires o perspectivas en el tratamiento del mismo, pues se convierte en el vehículo idóneo para expresar sus convicciones más íntimas. La narración se sitúa en época contemporánea y los personajes se ubican en el Madrid de finales del siglo XIX, principios del XX. Éstos pertenecen a la llamada clase alta, clase que la propia escritora conoce con total perfección por pertenecer a ella. Concepción Gimeno estructura su relato en nueve cortos capítulos; de uno a otro el lapso temporal se rompe y sitúa a la protagonista en otro lugar y en horas o días distintos al del capítulo anterior ${ }^{6}$. La protagonista, Luisa, es una mujer casada, que experimenta una tremenda fascinación por el marido de su amiga María; atracción mutua, pues éste, Carlos, insistirá una y otra vez a lo largo de la narración en la expresión de su amor por Luisa, hasta que, finalmente, Luisa lo rechace de forma definitiva. Argumento simple y que, sin embargo, proporcionará a Concepción Gimeno la oportunidad de reiterar de forma placentera algunas de las cuestiones que de forma repetitiva ha esbozado en sus ensayos.

La presencia de personajes femeninos es mayor que la de masculinos, pues en realidad el único que juega un papel destacado en la narración es el

ción Gimeno estudió la situación de la mujer durante los numerosos viajes emprendidos tanto en los países de nuestro entorno europeo como en las naciones del continente americano. Experiencia personal que complementa con la imprescindible documentación libresca y periodística.

6. El relato se desarrolla a lo largo de escasos meses y en escenarios diferentes, pues de Madrid la protagonista se desplaza a Biarritz -mes de septiembre-, primero, y más tarde a París, coincidiendo con la festividad de los Santos Difuntos -noviembre-. Estos espacios corresponden tanto a espacios públicos como privados, lo que permite a la autora describir, sin mucho detenimiento desde el madrileño paseo de El Retiro hasta la playa de Biarritz o el mausoleo de Abelardo y Eloísa en el cementerio de Père Lachaise de París, el preferido por literatos, artistas y amantes desgraciados. Mayor cuidado y atención presta Concepción Gimeno de Flaquer a la descripción de los recintos cerrados. En unos casos, como sucede en la descripción de la salita privada de la propia protagonista, porque a través de la misma nos ofrece el complemento idóneo para delinear su carácter, aficiones, su forma de ser, en suma. En otros -Teatro Español, salones de adineradas damas- el espacio geográfico le permite dirigir sus censuras hacia determinados comportamientos de sus contemporáneos. 
mencionado Carlos, abogado, artista, orador, poeta, un ser excepcional, en el decir de la protagonista. Carlos se encuentra casado con una mujer que responde al ideal que la mayoría de los hombres de la época aspira. Mujer bondadosa, preocupada no sólo por la felicidad de los suyos, sino también interesada por organizar las más ingeniosas iniciativas con el fin de socorrer a los más necesitados. Así, por ejemplo, María reúne en su casa a las más altas damas de la sociedad para coser ropa y donarla a los desfavorecidos por la fortuna ${ }^{7}$. Mujer de enorme bondad, pero escasa preparación intelectual, lo que motiva la incomunicación con su esposo. Concepción Gimeno plantea el problema del adulterio, analizando las posibles causas que pudieran, en el círculo social en que ella se mueve, favorecerlo. De ahí que la narración se inicie con la conversación que, durante un paseo en carruaje por los jardines de Rosales, mantienen la protagonista y su prima Mercedes. Plática que la autora utiliza para exponer situaciones y circunstancias que pueden desencadenar el temido adulterio. A través de esta conversación la autora nos ofrece distintos retratos de tipos femeninos y las circunstancias que motivaron su enlace matrimonial. La protagonista, Luisa, se casó con un potentado hacendado, Antonio Barolt, para salvar a su padre de la ruina económica. Hombre que no la satisface, pues como ella misma señala «Antonio no es malo, es un ser del montón, criatura para quien la existencia no tiene más objetivo que los deportes y el casino. Es un hombre abúlico, indiferente a la vida del espíritu» (Cap. I. $)^{8}$. Por el contrario, Mercedes contrajo matrimonio por amor. No obstante, las diferencias entre estos personajes femeninos se acentúan con el correr de los hechos, pues cada una de ellas representará un tipo de mujer. Luisa, la abanderada de las nuevas ideas; Mercedes, por su lado, responde a la mujer de carácter conservador, pero capaz de entender la necesidad de que la sociedad cambie respecto a la consideración de su propio género9. Concepción Gimeno describe a esta ultima en el primer

7. Concepción Gimeno de Flaquer expresa su desacuerdo ante unas prácticas caritativas que buscan la exhibición y el reconocimiento públicos. Así, la protagonista, señala, al acudir a casa de María a coser ropa para los necesitados, lo siguiente: «Creo que vengo aquí en miércoles por no desairarte, pero no me gusta la caridad colectiva, reglamentada. Para ejercerla no hay que agremiarse $[\ldots] \mathrm{La}$ mayor parte de las asociaciones benéficas que organizan las mujeres es por figurar; a la burguesa le halaga codearse con la aristócrata, y aprovecha una ocasión que no encuentra en su círculo; a la noble, título de nueva emisión, le satisface ejercer cargos honoríficos, disfrutar de homenajes que no le han de prodigar las aristócratas de elevada estirpe. Cuando llega una provinciana a Madrid le dicen sus amigas que entre en sociedades benéficas para adquirir relaciones» (Cap. V).

8. Más adelante, en el cap. VI, la novelista nos vuelve a ofrecer un retrato de este personaje: «El marido de Luisa era uno de esos hombres que pasan inadvertidos en todas partes. Ni elegante ni desaliñado, sin nada que destacara en él, su persona como su ser psíquico, incoloro, carecía de relieve».

9. En el transcurso de una conversación entre ambas se produce un intercambio de opinión sobre los necesarios cambios legislativos a favor de la mujer y Mercedes muestra interés por lo expuesto por 
capítulo de la novela de la siguiente manera: «Mercedes, su prima, frisaba en los cuarenta. Morena, de obscura cabellera, distinguíase por su aspecto señoril. Poseía inteligencia clara, no cultivada. Mujer de sentido práctico, de gran rectitud, no aceptaba distingos casuísticos; aconsejaba a su prima tratando de evitar lo que consideraba amoral, germen de infortunio, pero era benévola, como lo son las mujeres inmaculadas» (Cap. I.). Luisa, un poco más joven, era menos hermosa que Mercedes, pero a cambio poseía el fascinador encanto de un rostro expresivo, una complexión esbelta, de maneras exquisitas, vestida con enorme elegancia y poseedora de una amena e inteligente conversación. Mujer instruida gracias a la voluntad y tesón de su padre, que le procuró una sólida educación al hacerla cursar el bachillerato, dato de singular elocuencia, pues no nos consta, documentalmente, que hasta 1872 ninguna española hubiese obtenido este grado de instrucción ${ }^{10}$. Observemos que la conversación transcurre entre dos mujeres que han alcanzado una cierta madurez, Mercedes se acerca a los cuarenta años de edad; Luisa ha traspasado la frontera de los treinta. Edades que en el contexto de la época equivalen al alejamiento casi total de la juventud y de las fantasías y aspiraciones propias de la misma. Circunstancias que les proporcionan, a su vez, esa capacidad para analizar cómo se desarrolla su vida y enjuiciar los motivos que les han llevado a su realidad presente. De ahí que Luisa señale, al mencionar el frustrado matrimonio de Carlos con María, que el amor de madurez es más pleno que el de juventud, pues este último se fundamenta, especialmente, en la fascinación de la belleza femenina, más en la materia que en el espíritu. En la madurez, el amor sin peder ese componente de atracción sexual, se sustenta sobre todo en la afinidad de carácter, en las inquietudes y aficiones compartidas. Así lo corrobora tanto Luisa como el personaje Carlos en distintas ocasiones, como sucede,

Luisa: «Yo nunca me había ocupado de estas cosas; pero desde que te oigo hablar de ello, he pensado en que tengo tres hijas y que me conviene lo que proyectáis» (Cap. III). Ambas mujeres, tan diferentes entre sí, coinciden, sin embargo, en la necesidad de reformar las leyes que perjudican a la mujer, Mujeres que, con no poco realismo, son conscientes de que «Nuestra generación no lo ha de ver; entre nosotros cuesta trabajo arrancar la corteza que envuelve rutinas tradicionales, demoler lo caduco, lo arcaico. Somos misoneístas» (Cap. III). Concepción Gimeno deja entrever en este pasaje de su novela su aspiración a que la mujer asuma las razones de ese feminismo moderado que ella abandera, convencida como está de que las reivindicaciones feministas serán reconocidas con el transcurso del tiempo, tal como apostilla en Evangelios de la mujer: «El siglo XVIII proclamó los derechos del hombre; el XIX ha concedido a la mujer en algunos pueblos lo que aquí pedimos; el XX los otorgará» (1900: s. p.).

10. En El Siglo Médico (1872: 382) aparece la siguiente noticia: «En Barcelona acaba de recibir el grado de bachiller en artes después de unos brillantes exámenes la señorita Elena Maseras y Ribera, siendo según dice un colega de aquella ciudad, la primera en España que ha obtenido dicho grado» 
por ejemplo, en el capítulo II, cuando se produce una entrevista entre los personajes mencionados. Carlos se congratula al encontrar a Luisa rodeada de libros de claro contenido filosófico o feminista -Ruskin, Taine, Stuart Mill, Bebel, Rosler, Navicow, Minghetti, Bois, María Chéliga, Clemencia Royer, Marcela Tynaire, Teresa Cabriola, Olga Lodi, Margarita Duran, entre otras, señalando que «[...] Hacen muy mal los que se oponen a la cultura de la mujer; no conocen su propio interés. La comedia del matrimonio tiene largos entreactos, y una mujer insustancial no puede amenizarlos» (Cap. II). Cuestión que guarda estrecha relación con la definición que del matrimonio realiza en El problema feminista, «asociación de dos seres conscientes, libres e iguales» (1903: 6), concepción de la institución que regula por antonomasia las relaciones entre hombre y mujer realmente novedosa y no menos escandalosa para la época. Carlos y Luisa, desde su madurez, desde la libertad de pensamiento del que hacen gala y desde el plano de igualdad en que se desarrollan sus relaciones, podrían ejemplificar con total perfección el modelo de matrimonio que postula la escritora. No obstante, no debemos olvidar que ambos están casados y por lo tanto, no están en condiciones jurídicas y morales para alcanzar esa meta, por muy deseable que ésta se presente.

En sus ensayos Concepción Gimeno había combatido la generalizada idea de que la mujer es un ser débil, inclinado por su propia naturaleza a dejarse arrastrar por el camino de la perversión. La autora, coincidiendo con los postulados de Concepción Arenal, había sostenido que «la mujer es igual al hombre en fuerza moral» (La mujer española, 1877: 149), pues argumenta que sólo protegida con el escudo de la virtud, ésta es fuerte, honrada, digna y hace gala de un agudo sentido del deber. Si la mujer se desvía de este recto comportamiento es por carecer de la preparación intelectual adecuada. De ahí, su preocupación por liberarla de la ignorancia, ya que, como apunta la ensayista, «una mujer ignorante es un ser débil e indefenso: sin ideas, sin carácter, sin resolución y sin iniciativa» (1877: 137). Luisa encarna estas ideas; mujer de sólida preparación intelectual está convencida que la razón se impondrá a su inclinación por Carlos. La novelista centra su atención de la descripción del conflicto sentimental de la protagonista, los vaivenes emocionales que se suceden en su mente, en analizar los sentimientos que la embargan a lo largo de los distintos encuentros casuales que se producen entre ellos dadas las relaciones de amistad que unen a las dos familias. El capítulo segundo es muy significativo a este respecto, pues por primera vez Carlos expone abiertamente a Luisa su amor por ella, proclamando su satisfacción por haber hallado en Luisa la mujer soñada, la mujer cuyos pensamientos coinciden en los suyos propios. Era «una intelectual que, no encontrado atractivo en el visiteo a que son tan aficionadas 
las mujeres ignaras, dedicaba su tiempo a la lectura y a la contemplación de obras artísticas [...] era una mujer de claro criterio, libre de rutinas y prejuicios, un ser que se adaptaba a los ideales del progreso, un espíritu abierto a reformas e innovaciones [...] semejaba la mujer fuerte de un futuro Evangelio» (Cap. II). La proclamación de amor se produce después de que Luisa, aprovechando la condición de diputado en Cortes de Carlos, le solicite ayuda para corregir algunos artículos de los Códigos Civil y Penal que discriminan a la mitad de la humanidad. En la novela se alude al hecho de que la mujer española carezca en este tiempo de capacidad legal para administrar su fortuna o disponer del producto de su trabajo; se rechaza el distinto tratamiento que recibe el hombre y la mujer en el Código Civil, mientras que el Código Penal castiga más duramente a la mujer en caso de que el adulterio sea llevado a cabo por la misma. Igualmente se comenta la abolición en Italia del artículo 213 del Código de Napoleón, el que proclama la sumisión de la mujer al marido y la protección de él a la esposa. Cuestiones que Concepción Gimeno también ha expuesto en distintos textos, especialmente en su conferencia El problema feminista ${ }^{l 1}$. En la novela, la posición feminista de la autora se reafirma con su exigencia del sufragio femenino. En la mencionada conferencia, El problema feminista, Concepción Gimeno se sitúa en un feminismo moderado o conservador que busca la emancipación intelectual y económica de la mujer ${ }^{12}$. Un feminismo moderado que no exige el sufragio para la mujer, que no desea que ésta sea electora y elegible, y que rechaza, por ende, participar activamente en el juego político. Sin embargo, a la altura de 1909 la escritora avanza en sus posiciones y aunque sigue rechazando la participación de la mujer en las

11. En esta obra muestra su total rechazo a que los legisladores consideren a la mujer «Igual al hombre ante la ley penal e inferior ante la ley civil» (1903: 21). Especialmente delicada le parece la situación de la mujer casada, sometida por completo a la despótica voluntad del marido: «La tiranía marital puede prohibirle visitar a sus padres, disponer de su caudal, ser albacea, ejercer tutela y comparecer en juicio; el marido, amo y señor, está autorizado para interceptar la correspondencia de su esposa, obligarla a cambiar de nacionalidad, impedirla que coopere a la cultura general por medio de la prensa» 1903: 8). El tono enérgico de denuncia envuelve las argumentaciones de una escritora que es consciente del atraso en que se encuentra la sociedad española al respecto.

12. Concepción Gimeno enumera los ideales del feminismo moderado que ella abandera en su obra Evangelios de la mujer; $« 1^{\circ}$. Evitar todo obstáculo a las manifestaciones de las facultades intelectuales de la mujer; $2^{\circ}$. Educar esas facultades para que puedan utilizarse, teniendo en cuenta que las mentales, como las musculares, se atrófianse si no se ejercitan; $3^{\circ}$ Darle trabajo bien remunerado que la defienda de toda inmoralidad; $4^{\circ}$ Concederle la libre disposición del capital adquirido con su trabajo, por dote o herencia; $5^{\circ}$ Favorecer al sexo femenino en los talleres y fábricas, teniendo en cuenta que la mujer está más condenada por la naturaleza al dolor físico que el hombre; $6^{\circ}$. Destruir la trata de blancas, tan punible como lo fue en otros tiempos la trata de negros; $7^{\circ}$. Permitirle el derecho a ejercer las profesiones y cargos dignos de sus aptitudes, muy especialmente la medicina, para curar las enfermedades de las mujeres y las de los niños» (1900: 118-119). 
tribunas políticas, exige ser electora y, de esta manera, aupar al ámbito político a aquellos hombres más capacitados para defender los derechos de esa mitad de la humanidad que son las mujeres.

Tras el inicial rechazo de Luisa a las pretensiones amorosas de Carlos, en las que se cita explícitamente su condición de madre, los vaivenes sentimentales se suceden. Luisa se confiesa ante su prima, sin obviar la irresistible atracción que sobre ella ejerce Carlos: «Al adivinar Carlos que le quería, sentí rubor; hoy, que ha sospechado mi temperamento, siento indignación contra mí misma. No puedes calcular mis esfuerzos para que no me conozca. Procuro mistificarme, apareciendo fría para ocultarle mi ser fisiológico. Apago los rugidos de la bestia humana con frases espirituales, y, a pesar de ello, temo verme descubierta. Una ola de fuego abrasa mi corazón y mi cerebro» (Cap. III). No obstante, aun siendo consciente de que la materia se impone a su espíritu, su resolución es firme: "Yo no acudiré nunca a una cita» (Cap. III), aunque «[...] Muchas noches despierto llorando, porque la lucha del día me persigue en sueño; padezco convulsiones. Siento un infierno dentro de mí» (Cap. III). La insistencia de Carlos provocará la vacilación en el ánimo decidido de Luisa, que acabará albergando el deseo de encontrarse en París con su enamorado. Las circunstancias son favorables, pues Luisa, en desacuerdo con la educación que recibe su hija de la institutriz responsable de su instrucción, decide trasladarla a un pensionado francés, mientras su marido se desplaza a hacerse cargo de unas fincas que poseen en Andalucía. La infidelidad, pues, parece el desenlace final del relato. Sin embargo, la protagonista recobrará el control de sí misma y los principios éticos que han regido su vida hasta que se ve envuelta en el conflictivo enredo sentimental vivido, surgen con brío al contemplar la desesperación de su hija ante la perspectiva de quedarse en el mencionado centro de enseñanza parisiense. Luisa, parece desprenderse en ese mismo momento del velo que ha cubierto sus ojos, de esos sueños de alcanzar un amor correspondido y pleno al lado de Carlos. La protagonista decide ocuparse ella misma del cuidado y educación de la niña. Luisa, pues, renuncia, en un acto libre de voluntad, a satisfacer sus deseos de mujer, no por la asunción de unos preceptos religiosos o por la moral social imperante, sino por ser plenamente consciente de su deber y responsabilidad ante su propia hija. Conviene en este sentido resaltar que en ningún momento su situación de mujer casada condiciona su resolución, sino que ésta obedece por completo al amor que siente por su hija. Final que concuerda con algunas de las ideas expresadas por Concepción Gimeno en obras anteriores, cuando en La Mujer española, por ejemplo, señala que «Ante la púdica mirada de la niña, sentiréis reverdecer vuestros marchitos corazones, los cuales quedarán preparados para dar cabida a 
sentimientos levantados y generosos; si os halláis azotados por el huracán de las pasiones, la tranquila mirada de la niña devolverá la calma a vuestro agitado espíritu; la sonrisa que se dibuja en sus labios purpúreos os hará comprender que existe la felicidad en este mundo» (1876: 199). Fragmento que aclara perfectamente lo apuntado en el texto novelesco, pues describe el porqué de la resolución tomada por la protagonista de Una Eva moderna al contemplar el compungido rostro de su hija. Luisa, voluntariamente, se impone la misión de educarla personalmente. No debemos olvidar tampoco que Concepción Gimeno se había mostrado contraria a que la sociedad impusiese a la mujer un papel determinado, sobre todo si este papel quedaba reducido a la mera procreación y cuidado tradicional del hogar doméstico. La escritora abogaba por la necesidad de que fuera la propia mujer, pertrechada de una educación y conocimientos adecuados, la que eligiera su propio camino -«No le impongáis su misión; que se la imponga ella espontáneamente», había sostenido en La mujer española (1876: 59)-. Luisa ejemplifica ese ideal de mujer que Concepción Gimeno esboza en muchos de sus ensayos y novelas, una mujer plena, con necesidades espirituales e intelectuales, pero una mujer capaz también de reconocer y sentir el magnetismo sexual de Carlos. Mujer fuerte, instruida, con fuertes valores éticos, comprometida con su sociedad, pero débil y egoísta, en ocasiones, ante el vehemente sentimiento amoroso. Personaje, en suma, de carne y hueso, con luces y sombras, que parece correr irremediablemente hacia un comportamiento indecoroso y termina por agrandarse ante los ojos del lector al obrar de acuerdo con sus propios principios éticos.

Parece evidente la concordancia ideológica existente entre lo expuesto en los ensayos feministas y la novela analizada. Ahora bien, Concepción Gimeno de Flaquer es consciente en todo momento de que está ofreciendo a sus lectores un relato novelesco, de ahí su interés en la presentación de los caracteres, en la descripción de un espacio que, en ocasiones, simboliza o complementa el temperamento de sus principales figuras o su preocupación por ofrecer una historia con un lenguaje acorde con las modas de la primeras décadas del siglo $\mathrm{XX}^{13}$. Concepción Gimeno en esta novela parece

13. Reproducimos, a modo de ejemplo, el siguiente fragmento, donde se puede observar la cuidadosa selección y uso de un vocabulario muy a gusto de la moda literaria de este momento: «Artístico boudoir, tapizado de azul, transparentábase al través de blanco stort en el cuarto bajo de suntuosa casa de la calle de la Lealtad. Los postigos mal cerrados, permitían al transeúnte incompleto curioseo. Una planta de amplias hojas, fulgurando con sus flores la luz desde un tibor de mayólica, erguido sobre dorada columna, iluminaba, en unión de un foco eléctrico del copete del espejo de la chimenea, aquella habitación, cayendo los rayos de luz sobre cuadros de Goya y de Ribera, sobre otomana sillería, coquetón escritorio de nogal y caprichosa vitrina en forma de litera, que guar- 
seguir las huellas de Gertrudis Gómez de Avellaneda y Emilia Pardo Bazán, quienes trazaron en Sab y Dos mujeres, la primera, y en Doña Milagros y Memorias de un solterón, la segunda, un tipo de relato novelesco que, sin descuidar los resortes del género, les permitiese insertar sus convicciones y aspiraciones más íntimas. Tres escritoras fuertemente comprometidas en el esfuerzo de alterar las estructuras mentales de esa sociedad arcaica en la que no sólo dieron a conocer sus trabajos ensayísticos o literarios, sino que también buscaron un protagonismo a fin de hacer oír sus reivindicaciones feministas a la sociedad de su época.

daba figurinas de Tanara, ánforas etruscas, páteras áticas, una esfinge y algún fragmento egipcio, que debió pertenecer a obelisco monolítico [...] Cómoda chaisse-longue estilo Imperio y mullido diván oriental, con profusión de almohadones de distintos tamaños, delataban coquetería y afán de bienestar de elegante dama» (Cap. II). 


\section{BIBLIOGRAFÍA}

Ayala, $\mathrm{M}^{\mathrm{a}}$ de los Ángeles, «La mujer española, de Concepción Gimeno de Flaquer», en Actas del III Coloquio de la Sociedad de Literatura Española del Siglo XIX: Lectora, heroína, autora (La mujer en la literatura española del siglo XIX), Barcelona, PPU, 2005, pp. 13-22.

Bieder, M. «Concepción Gimeno de Flaquer (1852?-1919)», en Spanish Women Writers: a Bio-Bibliographical Source Book, Westport, Greenwood Press, 1993, pp. 219-229.

—. «Feminine Discourse/Feminist Discourse: Concepción Gimeno de Flaquer» Romance Quaterly, 37 (1990), pp. 459-477.

Catálogo de publicaciones periódicas madrileñas existentes en la Hemeroteca Municipal de Madrid, 1661-1930, Madrid, Artes Gráficas Municipales, 1933.

Chozas Ruiz-Belloso, Diego, «La mujer según el Álbum Ibero.Americano (1890- 1891) de Concepción Gimeno de Flaquer», Espéculo. Revista de estudios literarios (Revista Digital Cuatrimestral), 29 (2005).

Gimeno De Flaquer, Concepción, La mujer española. Estudios acerca de su educación y sus facultades intelectuales. Precedidos de una carta prólogo al Excmo. Sr. D. Leopoldo Augusto Cueto Madrid, Imprenta y Librería de Miguel Guijarro, 1877.

—. La mujer juzgada ante el hombre, Zaragoza, Ariño, 1882.

—. La mujer juzgada por una mujer, Barcelona, Tasso, 1882 ( $3^{\mathrm{a}}$ ed.).

- ¿Culpa o expiación? Novela original con retrato y biografía de la autora, México, Oficina Tipográfica de la Secretaría del Fomento, 1890 ( $4^{\mathrm{a}}$ ed.).

- Mujeres. Vidas paralelas, Madrid, Tipografía de Alfredo Alonso, s. a. [1893] (4 $4^{\mathrm{a}}$ ed.).

- Ventajas de instruir a la mujer y sus aptitudes para instruirse. Disertación leída en el Ateneo de Madrid en la noche del 6 de mayo de 1895, Madrid, Imprenta de Francisco G. Pérez, 1896.

—. La mujer intelectual, Madrid, Imprenta del Asilo de Huérfanos, 1901.

- El problema feminista. Conferencia pronunciada en el Ateneo de Madrid, Madrid, Imprenta de Juan Bravo, 1903.

-. Una Eva moderna, El Cuento Semanal, Año III, 152 (26 de noviembre de 1909), s. p.

Hibbs-Lissorgues, S., «María Concepción Gimeno de Flaquer: une philosophe et créatice du XIX ${ }^{\mathrm{eme}}$ siècle», F. Etienvre (ed.), Colloque International Regards sur les Espagnoles Créatrices (XVIII-XX siècles), Parigi, Université de Paris III-Sorbonne Nouvelle, 2006, pp. 119-135. 
Muñoz Olivares, C. y M. Villalba Álvarez, «Concepción Gimeno de Flaquer y Sofía Casanova: novelistas olvidadas de principios de siglo», en M. Villalba Álvarez (ed.), Mujeres novelistas en el panorama literario del siglo XX, Cuenca, Universidad de Castilla-La Mancha, 2000, pp. 95-106.

Ramos Escandón, Carmen, «Concepción Gimeno de Flaquer: identidad nacional y femenina en México, 1880-1900», Arenal, vol. 8, 1 (2000), pp. 365-378.

Simón Palmer, $\mathrm{M}^{\mathrm{a}}$ del Carmen, Las escritoras españolas del siglo XIX. Catálogo bio-bibliográfico, Madrid, Castalia, 1991, pp. 363-374. 